\title{
Assessing community midwives' knowledge of PE/E management in Sindh, Pakistan
}

Population Council

Follow this and additional works at: https://knowledgecommons.popcouncil.org/departments_sbsr-rh

Part of the Demography, Population, and Ecology Commons, Family, Life Course, and Society Commons, International Public Health Commons, and the Women's Health Commons How does access to this work benefit you? Let us know!

\section{Recommended Citation}

"Assessing community midwives' knowledge of PE/E management in Sindh, Pakistan," Ending Eclampsia Country Brief. Washington, DC: Population Council, 2017. 


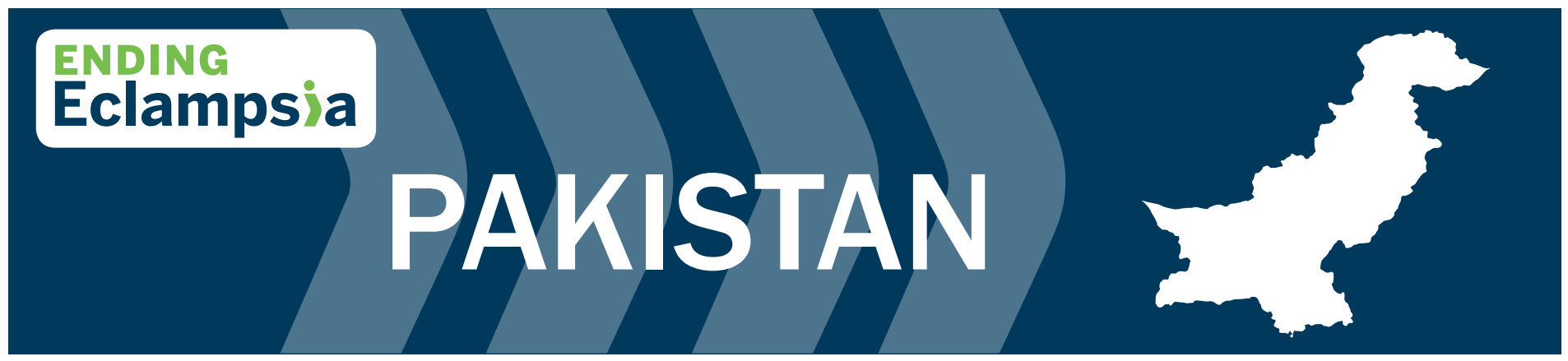

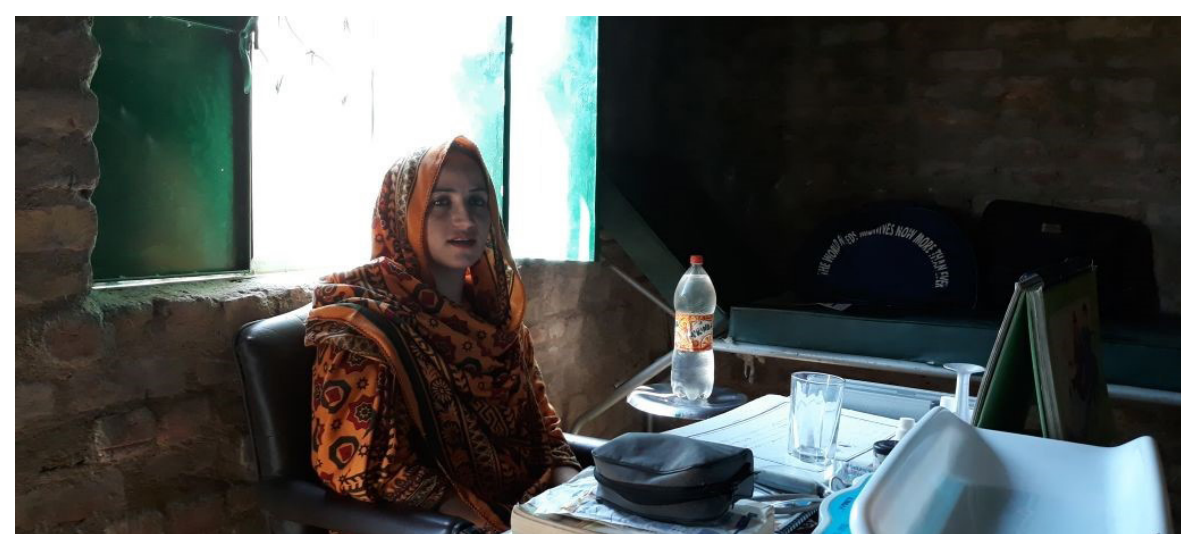

\section{Assessing Community Midwives' Knowledge of PE/E Management in Sindh, Pakistan}

Despite efforts to reduce preventable maternal and neonatal mortality, Pakistan's maternal mortality ratio is 276 deaths per 100,000 live births and the country's neonatal mortality is 55 per 1,000 live births - both considered high compared to other countries in the region (Pakistan Demographic and Health Survey (PDHS) 2006-07).

Eclampsia is the third major cause of maternal deaths in Pakistan. To improve access to maternal, neonatal, and child health (MNCH) services, in 2007 the Government of Pakistan introduced a cadre of trained community midwives (CMWs) to work in rural communities. The CMWs are trained skilled birth attendants (SBAs) who are equipped to conduct a normal delivery in clean and safe conditions.

The Population Council conducted a landscape analysis to assess the knowledge and practices of CMWs in Tando Allahyar, a rural district of Sindh, on the prevention, detection, and management of pre-eclampsia, severe pre-eclampsia, and eclampsia, as well as gaps and challenges around the prevention and treatment at the provincial and district levels in Pakistan. This brief shares the findings of that assessment, and provides recommendations that would minimize the gaps in maternal health services.

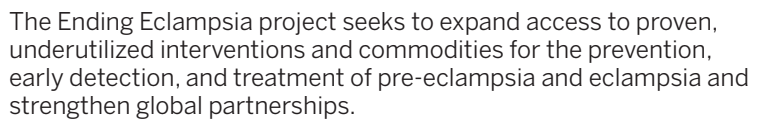

\section{Highlights}

- Pre-eclampsia (PE) is a condition in pregnant women marked by an increase in blood pressure and protein in urine after 20 weeks gestation.

- High-quality antenatal care can prevent or detect preeclampsia at an early stage, and prevent its progression to eclampsia.

- Eclampsia is a life-threatening condition characterized by convulsions in pregnant women with PE.

- Women in developing countries are 300 times more likely to die from eclampsia than women in developed countries.

- $\quad$ Pre-eclampsia and eclampsia (PE/E) can be managed by administering antihypertensive drugs and magnesium sulfate $\left(\mathrm{MgSO}_{4}\right)$.

- $\mathrm{MgSO}_{4}$ is the safest and most effective drug for controlling seizure in severe $\mathrm{PE} / \mathrm{E}$, and is one of the 13 UN Life-Saving Commodities for Women and Children.

- $\quad$ PE/E and other hypertensive disorders in pregnancy increase the risk of pre-term births.

- Improved prevention, increased detection, and effective treatment of PE/E can prevent unnecessary maternal and newborn deaths.
The Population Council conducts research and delivers solutions that improve lives around the world. Big ideas supported by evidence: It's our model for global change. popcouncil.org (C) 2017 The Population Council, Inc.
POPULATION COUNCIL

Ideas. Evidence. Impact. 


\section{FINDINGS}

Forty CMWs currently working in District Tando Allahyar and registered with the $\mathrm{MNCH}$ program were interviewed for the assessment. The majority of the CMWs are young: 72 percent were younger than 30 years of age.

Nearly three-fourths of the CMWs had established clinics at their residences ("health homes") to conduct deliveries. About 17 percent had set up clinics elsewhere while the rest did not have clinics.

The majority of the CMWs had been working for less than two years. Almost two-fifths had not conducted any delivery, while one-fifth had delivered more than four babies.

Findings showed the CMWs had a high level of knowledge of quality antenatal care (ANC) and postnatal care (PNC). However, the majority failed to mention the need for measuring and recording blood pressure during every ANC visit. See Figure 1 for more information.

\section{FIGURE 1: CMWs' knowledge of identifying PE/SPE during ANC and PNC based on giving correct answers to standard questions}

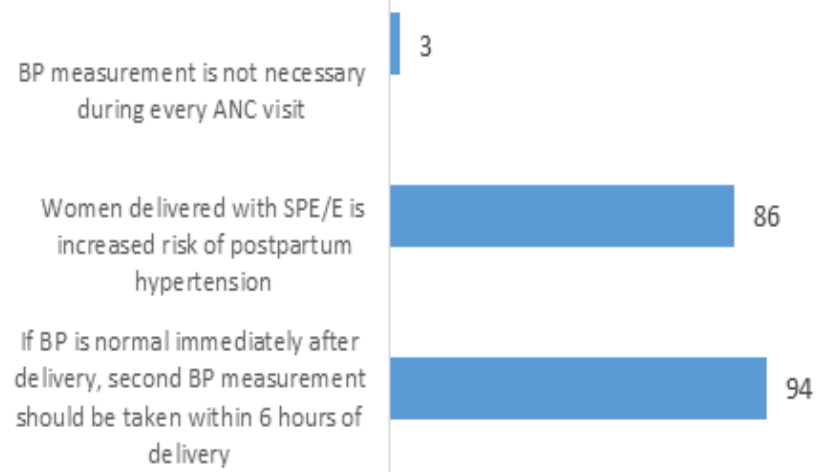

However, the level of knowledge regarding danger signs during pregnancy varied. More than half of the CMWs identified three danger signs during pregnancy, primarily high blood pressure, spotting, pallor or anemia. Knowledge regarding proteinuria, vaginal discharge, and blurred vision was poor. Only one-third of the women mentioned severe headache as a danger sign.

Researchers assessed CMWs knowledge of signs and symptoms of severe pre-eclampsia, and found more than four-fifths of the respondents could correctly identify the blood pressure reading that would determine severe pre-eclampsia. On the other hand, only two CMWs mentioned upper abdominal pain as a danger sign.
Nearly one-fifth of CMWs could not identify a single risk factor for SPE/PE. Only one-third mentioned previous history of hypertension during pregnancy as a risk factor.

When asked what they would do upon identifying a woman to be suffering from SPE/E, nearly three quarters of CMWs said they would refer the woman to a higher level health facility. Approximately three quarters of the CMW's reported that they refer clients to higher level facilities in case of diagnosing a woman with high blood pressure.

During their practice, 37 out of had never administered the loading dose of magnesium sulfate injection for managing severe pre-eclampsia.

\section{RECOMMENDATIONS}

For implementing the following key recommendations, the Ending Eclampsia project suggests the establishment of a task force comprised of members of professional bodies, health providers, civil society, and researchers who can periodically engage with policymakers to advocate for policy and programmatic changes:

- Competency-based skill development trainings for all CMWs to enhance their capacity to administer the loading dose of magnesium sulphate and refer clients to higher facilities for maintenance.

- Closer working relationships between community-based Lady Health Workers and CMWs should be encouraged to achieve deeper penetration of services and information.

- $\mathrm{PE} / \mathrm{E}$ management protocols, especially the administration of magnesium sulphate, should be widely distributed to ensure universal availability.

\section{CONTACT}

Ali Mohammad Mir

Associate, Director of Programs amir@popcouncil.org

Saleem Shaikh sshaikh@popcouncil.org

Mumraiz Khan mkhan@popcouncil.org

Irfan Masood imasood@popcouncil.org 